\title{
HARDT, Matthias, Gold und Herrschaft. Die Schätze europäischer Könige und Fürsten im ersten Jahrtausend
}

\section{Philippe Depreux}

\section{OpenEdition}

\section{Journals}

Édition électronique

URL : http://journals.openedition.org/ifha/833

DOI : $10.4000 /$ ifha. 833

ISSN : 2198-8943

Éditeur

IFRA - Institut franco-allemand (sciences historiques et sociales)

Référence électronique

Philippe Depreux, «HARDT, Matthias, Gold und Herrschaft. Die Schätze europäischer Könige und Fürsten im ersten Jahrtausend », Revue de I'IFHA [En ligne], Date de recension, mis en ligne le 01 janvier 2005, consulté le 22 septembre 2020. URL : http://journals.openedition.org/ifha/833 ; DOI : https://doi.org/ 10.4000/ifha.833

Ce document a été généré automatiquement le 22 septembre 2020.

(C)IFHA 


\title{
HARDT, Matthias, Gold und Herrschaft. Die Schätze europäischer Könige und Fürsten im ersten Jahrtausend
}

\author{
Philippe Depreux
}

Le renouvellement de l'historiographie du haut Moyen Âge occidental par l'intégration de réflexions et de problématiques propres à l'anthropologie historique va de pair avec un regain d'intérêt pour les pratiques en matière de don, comme en témoignent, en particulier, les travaux du groupe international de recherche sur les tranferts fonciers au haut Moyen Âge. Le trésor royal ne pouvait rester en marge de cette réflexion : la thèse soutenue par M.H. devant l'université de Marbourg en 1999, dont le présent livre est issu, vient heureusement enrichir une réflexion sur les trésors également menée par d'autres - outre la journée d'études du 10 juin 2005 organisée à l'Institut historique allemand de Paris avec, entre autres, le soutien de la MHFA (cf. le compte rendu supra, on peut en particulier renvoyer à Sauro Gelichi et Cristina La Rocca (dir.), Tesori. Forme di accumulazione della ricchezza nell'alto medioevo (secoli V-XI), Roma, 2004). Le présent travail présente l'intérêt de rassembler les sources narratives et archéologiques concernant les trésors des rois « barbares » en comparant leurs pratiques à ce que l'on sait de Byzance. Un corpus important est ici rassemblé. Rien que pour cela, ce travail revêt l'intérêt d'un ouvrage de référence. Il ne s'agit toutefois pas d'une enquête d'histoire de l'art, mais d'une recherche visant à mieux comprendre le rôle que jouaient de tels trésors dans les sociétés du haut Moyen Âge. Par conséquent, l'auteur s'intéresse en tout premier lieu aux symboles de pouvoir que représentent les objets précieux : mettre la main sur le trésor royal, c'est en fait prendre le pouvoir. M.H. s'intéresse tout à la fois au contenu des trésors (insignes de la royauté et autres bijoux, monnaies et lingots ou, encore, services de table, mais aussi tissus, armes, livres et reliques), à l'origine des biens versés au trésor royal (tributs et impôts, cadeaux et confiscations), aux lieux de dépôt des trésors et au personnel chargé de les garder, et, enfin, à l'usage qu'en faisait le roi : pour se mettre en valeur par la somptuosité de son apparence ou 
par la qualité des présents qu'il pouvait faire. Il s'agit par conséquent d'une approche, bien que ponctuelle, de la société du haut Moyen Âge dans son ensemble. Certes, le constat selon lequel des caisses bien remplies constituent l'une des conditions d'un gouvernement prospère (p. 300) s'avère assez attendu. "L'énigme du don » posée par Maurice Godelier (Paris, 1996) demeure en partie. Il y a donc matière à poursuivre l'enquête, notamment sur les rapports entre les rois et leurs Grands (les échanges de cadeaux lors des grandes assemblées faisant, en quelque sorte, de chacun l'obligé de l'autre). Le remplacement affirmé des biens meubles par les biens fonciers, présenté in fine comme processus de "féodalisation » de la société occidentale, mériterait d'être affiné. Il n'empêche que ce livre offre une analyse bien documentée tentant de faire la synthèse (en fait : un grand écart) entre l'analyse stylistique des objets précieux, l'histoire économique et sociale (avec, comme pomme de discorde, la question de l'impôt) et l'histoire du pouvoir royal, entre réalités et représentations.

Philippe DEPREUX (MHFA) 